\title{
Water in Sport: City of Greater Geelong
}

\section{Introduction}

During 2018-2020, the City of Greater Geelong partnered with VicHealth to improve access to water and create healthy drink environments in 7 local sport and recreation facilities.

The facilities we worked with included:

$\rightarrow$ Balyang Par 3 Golf Course

$\rightarrow$ Barwon Valley Activity Centre

$\rightarrow$ Carousel

$\rightarrow$ Geelong Arena

$\rightarrow$ Lara Aquatic Centre

$\rightarrow$ Leisuretime

$\rightarrow$ Splashdown

\section{Objectives}

$\rightarrow$ Increase the promotion and supply of water and reduce the availability and supply of sugary drinks in our community sports and recreation facilities. (>50\% GREEN drinks like water and $<20 \%$ RED sugary drinks)

$\rightarrow$ Strengthen council policies and practices to enable longerterm changes to healthy drinks environments across council-owned sport and recreation facilities.
The Healthy Choices: food and drink classification guide uses a traffic light system to classify foods and drinks as:

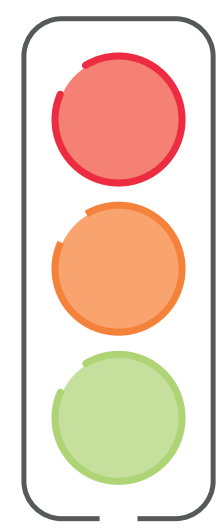

RED: Limit intake

AMBER: Choose carefully

GREEN: Best choice
Why

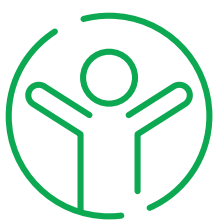

City of Greater Geelong has a

commitment to supporting the health and wellbeing of our community.
The environments in which we live, work, learn, and play are key drivers of the types of food and drink we consume. Local governments can play a key role in implementing policies and practices to improve local food and drink environments.
There is community support and expectation for healthy food and drinks $-75 \%$ of customers surveyed from all Water in Sport councils believed that sport and recreation facilities should promote healthy eating. 


\section{Outcomes}

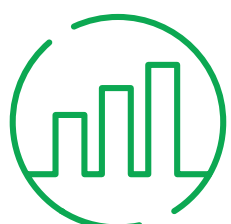

Overall, availability of 'GREEN' drinks increased from $48 \%$ to $53 \%$ of all drinks and 'RED' drinks decreased from $29 \%$ to $12 \%$ of all drinks.

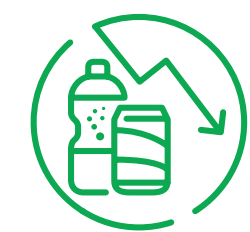

The Carousel sales of 'RED' drinks decreased by 10\% between March 2018 and February 2020.

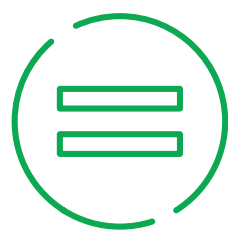

Balyang Par 3 Golf Course had no change in total drinks revenue between March 2018 and February 2020.

\section{Recommendations for creating healthy food retail environments in your community}

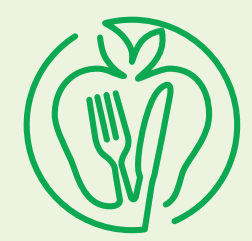

Use the VicHealth toolkit for creating healthy food and drink environments in community

food retail outlets.

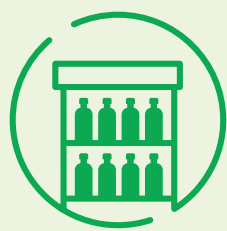

Start by trialing a small 'quick win' which is easy to implement and unlikely to cause revenue loss, such as rearranging the fridge to put 'GREEN' drinks at eye-level.

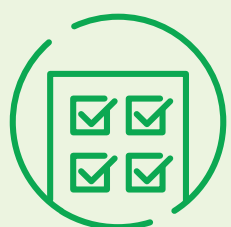

Develop healthy food environment policies and procedures for councils and facilities.

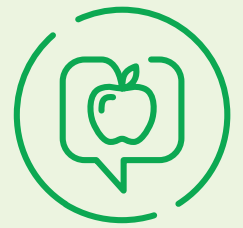

Contact the Healthy Eating Advisory Service for practical implementation support.

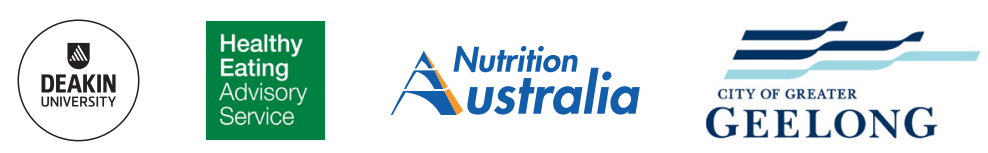

